JOURNAL OF GEOPHYSICAL RESEARCH: SPACE PHYSICS, VOL. 118, 5244-5254, doi:10.1002/jgra.50475, 2013

Copyright by the American Geophysical Union. Larquier, S. de, P. Ponomarenko, A. J. Ribeiro, J. M. Ruohoniemi, J. B. H.
Baker, K. T. Sterne, and M. Lester (2013), On the spatial distribution of decameter-scale subauroral ionospheric
irregularities observed by SuperDARN radars, J. Geophys. Res. Space Physics, 118, 5244-5254, doi:10.1002/jgra.50475.

\title{
On the spatial distribution of decameter-scale subauroral ionospheric irregularities observed by SuperDARN radars
}

\author{
S. de Larquier, ${ }^{1}$ P. Ponomarenko, ${ }^{1,2}$ A. J. Ribeiro, ${ }^{1}$ J. M. Ruohoniemi, ${ }^{1}$ J. B. H. Baker, ${ }^{1}$ \\ K. T. Sterne, ${ }^{1}$ and M. Lester ${ }^{3}$ \\ Received 25 March 2013; revised 23 July 2013; accepted 24 July 2013; published 9 August 2013.
}

[1] The midlatitude Super Dual Auroral Radar Network (SuperDARN) radars

regularly observe nighttime low-velocity Sub-Auroral Ionospheric Scatter (SAIS) from decameter-scale ionospheric density irregularities during quiet geomagnetic conditions. To establish the origin of the density irregularities responsible for low-velocity SAIS, it is necessary to distinguish between the effects of high frequency (HF) propagation and irregularity occurrence itself on the observed backscatter distribution. We compare range, azimuth, and elevation data from the Blackstone SuperDARN radar with modeling results from ray tracing coupled with the International Reference Ionosphere assuming a uniform irregularity distribution. The observed and modeled distributions are shown to be very similar. The spatial distribution of backscattering is consistent with the requirement that HF rays propagate nearly perpendicular to the geomagnetic field lines (aspect angle $\leq 1^{\circ}$ ). For the first time, the irregularities responsible for low-velocity SAIS are determined to extend between 200 and $300 \mathrm{~km}$ altitude, validating previous assumptions that low-velocity SAIS is an F-region phenomenon. We find that the limited spatial extent of this category of ionospheric backscatter within SuperDARN radars' fields-of-view is a consequence of HF propagation effects and the finite vertical extent of the scattering irregularities. We conclude that the density irregularities responsible for low-velocity SAIS are widely distributed horizontally within the midlatitude ionosphere but are confined to the bottom-side F-region.

Citation: de Larquier, S., P. Ponomarenko, A. J. Ribeiro, J. M. Ruohoniemi, J. B. H. Baker, K. T. Sterne, and M. Lester (2013), On the spatial distribution of decameter-scale subauroral ionospheric irregularities observed by SuperDARN radars, J. Geophys. Res. Space Physics, 118, 5244-5254, doi:10.1002/jgra.50475.

\section{Introduction}

[2] The geomagnetic midlatitude ionosphere is typically defined as a buffer zone between the equatorial and auroral regions, with boundaries that vary with geomagnetic activity. During quiet geomagnetic periods $\left(K_{p}<2\right)$, the midlatitude ionosphere extends approximately from $30^{\circ}$ to $60^{\circ}$ geomagnetic latitude. The quiescent midlatitude ionosphere is mainly controlled by photoionization and transport processes [Heelis, 2004] such as traveling ionospheric disturbances [e.g., Tsugawa et al., 2007] and neutral winds [e.g., Titheridge, 1995]. External forcing by magnetospheric electric fields is largely absent from the quiescent midlatitude \footnotetext{
USA.

${ }^{1}$ SuperDARN HF Radar Group, Virginia Tech, Blacksburg, Virginia,

${ }^{2}$ Institute of Space and Atmospheric Studies, University of Saskatchewan, Saskatoon, Canada.

${ }^{3}$ Department of Physics and Astronomy, University of Leicester, Leicester, UK.
}

Corresponding author: S. de Larquier, SuperDARN HF Radar Group, Virginia Tech, Suite 1033, 1901 Innovation Drive, Blacksburg, VA 24061, USA. (sdelarquier@vt.edu)

(C2013. American Geophysical Union. All Rights Reserved. 2169-9380/13/10.1002/jgra.50475 ionosphere due to the effect of shielding in the Alfvén layers [e.g., Kelley et al., 1979; Huba et al., 2005].

[3] The ionosphere is populated by plasma density irregularities. These irregularities result from plasma instabilities driven by combinations of plasma drifts, density and temperature gradients, electric fields, and winds [e.g., Fejer and Kelley, 1980]. These plasma density fluctuations cover a wide range of scale sizes, spatial distributions, and time scales. At midlatitudes, both plasma and neutral processes are believed to be involved in generating and sustaining ionospheric irregularities. Processes such as the Perkins instability, the Kelvin-Helmholtz instability, and internal gravity waves have been cited to explain observations [e.g., Kelley, 2009, ch. 6]. These mechanisms lead to irregularities with scale sizes ranging from tens of kilometers down to centimeters [e.g., Tsunoda, 1988].

[4] Depending on their scale sizes, ionospheric irregularities can be observed by a variety of techniques, both ground- and space-based. For instance, Global Positioning System scintillation provides measurements of irregularities with scale sizes of hundreds of meters [e.g., Fremouw et al., 1977]. Top-side sounders are also very common instruments observing mesoscale to large-scale ionospheric irregularities above $500 \mathrm{~km}$ altitude [e.g., Su et al., 2006]. 
[5] A conventional technique for studying decameterscale irregularities is based on backscatter echoes observed by high frequency (HF) radars [e.g., Oksman et al., 1979]. The Super Dual Auroral Radar Network (SuperDARN) is a chain of HF radars covering middle and high latitudes in both hemispheres. SuperDARN radars provide continuous observations of ionospheric dynamics [e.g., Greenwald et al., 1995; Chisham et al., 2007]. They operate at frequencies between 8 and $18 \mathrm{MHz}$, making them sensitive to backscatter from decameter-scale quasiperiodic structures. These quasiperiodic structures can be due to ionospheric plasma density irregularities in the E- and F-regions (responsible for ionospheric backscatter) or due to roughness at the Earth's surface (responsible for ground backscatter). Ground backscatter occurs after the HF signal from the radar is refracted by the ionosphere down to the ground.

[6] In the case of ionospheric backscatter from the Fregion, plasma density irregularities are typically highly aligned with the geomagnetic field lines due to the large difference in parallel and orthogonal ambipolar plasma diffusion coefficients [e.g., Hysell et al., 1996]. Consequently, they are only observed when the incident HF wave vector is nearly perpendicular to the geomagnetic field lines, a criterion referred to as the aspect condition. When propagation conditions are conducive to observing ionospheric irregularities, SuperDARN radars can measure their drift velocities via Doppler shift of the backscattered signal. At high latitudes, the drift velocities are on the order of hundreds to thousands of meters per second. The motion is caused mostly by $\mathbf{E} \times \mathbf{B}$ drift of the ionospheric plasma such that they can be used to infer electric fields and the large-scale plasma convection [e.g., Ruohoniemi and Baker, 1998]. With the expansion of SuperDARN to midlatitudes (see Figure 1), we have acquired new and dramatic views of such well-known subauroral disturbance phenomena as Sub-Auroral Polarization Streams [e.g., Oksavik et al., 2006; Grocott et al., 2011; Clausen et al., 2012; Kunduri et al., 2012].

[7] More surprisingly, the midlatitude SuperDARN radars have revealed active irregularity formation during quiet geomagnetic periods [e.g., Ribeiro et al., 2012; Kane et al., 2012]. The backscatter associated with such irregularities has been termed Sub-Auroral Ionospheric Scatter (SAIS) [Ribeiro et al., 2012]. Greenwald et al. [2006] reported recurring decameter-scale irregularities with low drift velocities $(<100 \mathrm{~m} / \mathrm{s})$ in the quiet time midlatitude nightside ionosphere observed with the first midlatitude SuperDARN radar located at Wallops Flight Facility, Virginia. They suggested that the Temperature Gradient Instability (TGI) [Hudson and Kelley, 1976] could be responsible for generating such irregularities. The authors relied on colocated observations by the Millstone Hill Incoherent Scatter Radar (ISR) and the Wallops SuperDARN radar, which showed opposed temperature and density gradients, a geometry that yields a positive growth rate for the TGI. The opposed gradients were attributed to the ionospheric projection of the plasmapause. However, a thorough statistical survey by Ribeiro et al. [2012] demonstrated that these irregularities are observed at latitudes far equatorward of auroral regions and the plasmapause projection. Using 3 years of data from the Blackstone SuperDARN radar, Ribeiro et al. [2012] showed that the low-velocity SAIS associated with these irregularities is confined to local night and occurs on $\sim 70 \%$ of nights.
[8] One important point of uncertainty in these studies arises from the difficulty in deriving precise SuperDARN backscatter geographical and altitude information. Because the ionosphere refracts HF signals, propagation does not follow a strictly line-of-sight path. The findings of Greenwald et al. [2006] relied on the conventional but unverified assumption that the observed irregularities are located in the F-region. Additionally, when studying the geographic distribution of HF ionospheric backscatter, corrections for propagation effects are rarely applied. Resolving the true altitude and geographic extent of ionospheric irregularities is crucial to inferring their potential sources.

[9] The high occurrence rate and large geographical spread of these quiet time midlatitude irregularities make them an important, yet poorly understood, part of nighttime ionospheric dynamics. The purpose of this paper is to resolve the HF propagation effects in the observation of backscatter in order to determine the limiting factors in the horizontal and vertical extent of the irregularities. To achieve this objective, we rely on data from the Blackstone SuperDARN radar and apply ray-tracing analysis of HF propagation based on empirical models of the ionosphere and geomagnetic field. The findings from this study will serve as a necessary initial step toward resolving the mechanisms responsible for generating the observed quiet time nightside midlatitude irregularities.

[10] For this study, we combine the data analysis methods presented in section 2.1 and ray-tracing model from section 2.2 with the propagation concepts detailed in section 2.3. In section 3, the ray tracing is compared with experimental scatter distributions in azimuth, range, and elevation to analyze the importance of the spatial irregularity distribution and HF propagation in generating the observed characteristics of low-velocity SAIS. We interpret the backscatter distributions in terms of the spatial distribution of ionospheric irregularities in section 4 .

\section{Methods and Tools}

\subsection{Data Sets and Analysis}

[11] SuperDARN radars consist of an electronically phased linear antenna array operated at frequencies between 8 and $18 \mathrm{MHz}$. A full field-of-view scan is completed every 1-2 min. Each scan is divided into 16 to 24 beams stepped in azimuth. Each beam is binned into $45 \mathrm{~km}$ slant-range gates: the slant range represents time-of-flight (group range) of the backscattered signal with respect to the radar. In the case of HF propagation, the exact location of the scatterers is a complex function of the group range, altitude of the scatter, and bending of the propagation path due to ionospheric refraction. Each slant-range gate stores a measure of the power, line-of-sight Doppler velocity, spectral width and elevation angle of the backscatter. The position of the backscatter is estimated with a simple linear model which determines altitude and elevation as a function of slant range to find ground projections. Geomagnetic coordinates of the backscatter projection are calculated with the Altitude Adjusted Corrected Geomagnetic Coordinates model [Baker and Wing, 1989].

[12] The Blackstone radar $\left(37.10^{\circ} \mathrm{N},-77.95^{\circ} \mathrm{E}\right)$ has been operating since February 2008. Its field-of-view provides good coverage of the midlatitude ionosphere for magnetic invariant latitudes $\Lambda>50^{\circ}$. The Blackstone radar was 


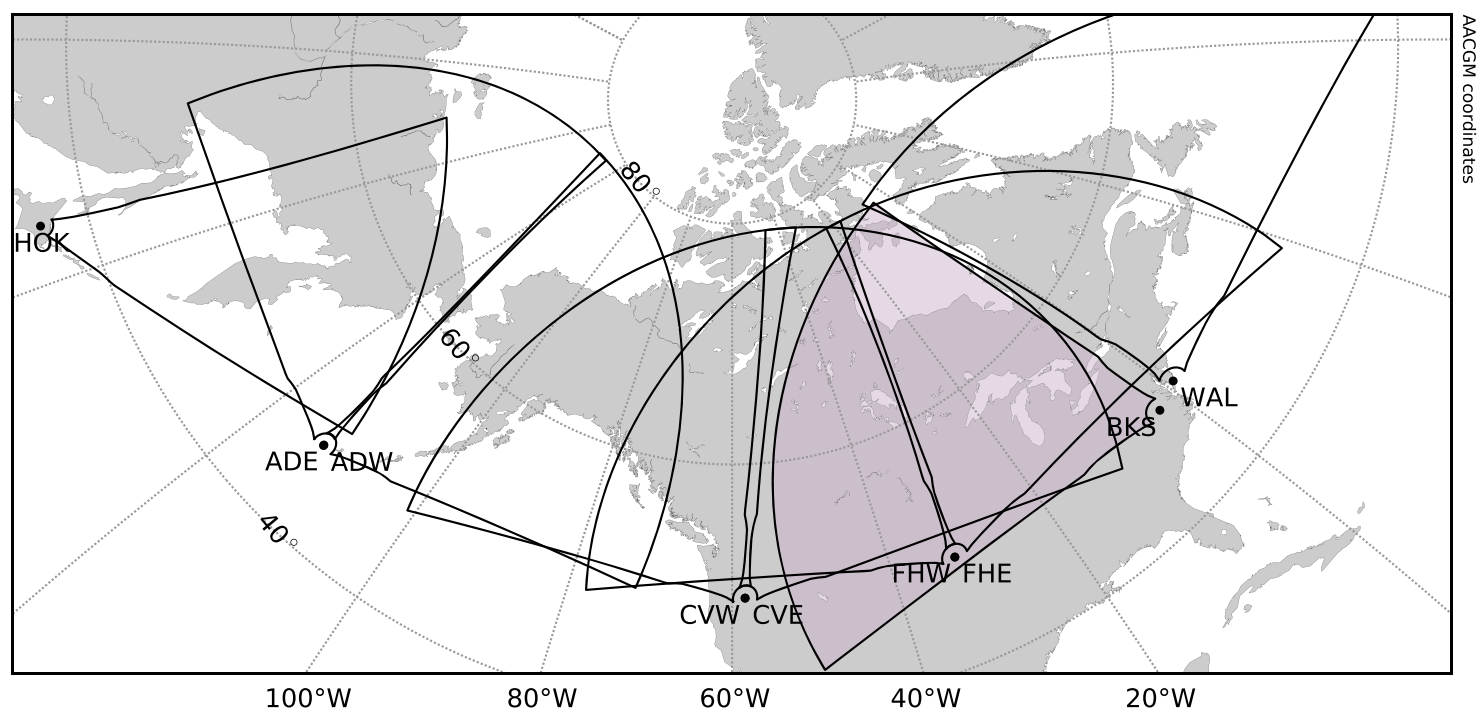

Figure 1. Midlatitude SuperDARN radar coverage in the Northern Hemisphere as of March 2013. The field-of-view of the Blackstone radar (BKS) is highlighted.

chosen for this study over the Wallops radar used by Greenwald et al. [2006] because it is the only midlatitude radar currently providing validated elevation angle measurements, which is an important parameter for analyzing HF propagation characteristics. The elevation angle is measured through the phase difference between the main antenna array and a secondary interferometer array located in front or behind the radar [Milan et al., 1997].

[13] Figure 2 shows complete scans from the Blackstone (bks) and Wallops (wal) radars projected onto a geomagnetic coordinate system, as well as time series of the slant-range distribution of the backscatter for selected beams. Figure $2 \mathrm{a}$ displays the backscatter power as a function of azimuth and range for a single scan at 8:00 universal time (UT) on 28 October 2011. In Figures 2b and 2c, beams 16 and 4 of the Blackstone and Wallops radars are selected and the observed velocity distributions plotted versus time. Positive (negative) velocities indicate movement toward (away from) the radar. In all three panels, the occurrence of ionospheric backscatter is indicated by the boxed regions.

[14] The time series of Figures $2 b$ and 2c show typical features observed by the midlatitude SuperDARN radars during quiet periods. In both panels, the first patch of scatter at 00:00 UT, which starts at $1500 \mathrm{~km}$ slant range and moves away from the radar as time passes, is ground scatter. Ground scatter is observed when the HF signals are reflected from the ionosphere down to the ground and part of the signal is scattered back to the radar along the same path by the rough ground surface. This type of scatter is prominent during the day, as seen in the large patch of ground scatter between the day-night terminators (dashed traces marking the transition between shaded and nonshaded areas in Figures $2 \mathrm{~b}$ and $2 \mathrm{c}$ ). Note that the sudden jumps in slant range of the observed scatter at 13:00 UT in Figure 2b and at 22:00 UT in Figure $2 \mathrm{c}$ are due to a change in operating frequency at the radars. During nighttime, the ionosphere is dominated by recombination, which decreases electron densities and raises the ionosphere, resulting in the ground scatter moving further away from the radar. Most nights, electron densities are too low to reflect the HF signals to the ground and ground scatter disappears. The activity is then dominated by ionospheric backscatter from geomagnetic field-aligned density irregularities as seen in the boxed regions. There is also backscatter from meteor trails at closer ranges $(<500 \mathrm{~km})$.

[15] The occurrence of ionospheric backscatter depends both on the presence of decameter-scale irregularities and the angle between the HF wave vector and the background geomagnetic field lines in the vicinity of irregularities. The angle between the plane perpendicular to the magnetic field lines and the radar wave vector is referred to as aspect angle. There is a large body of work relating to auroral Eregion aspect conditions reporting sensitivities from -10 to -15 dB/ ${ }^{\circ}$ [e.g., Bates and Albee, 1969; Foster et al., 1992]. Few studies provide quantitative information on F-region aspect sensitivity. Bates and Albee [1970] estimated that most of the F-region aspect-sensitive echoes where observed within $5^{\circ}$ of perpendicularity with the magnetic field. Their observations yielded an aspect sensitivity on the order of 5 $\mathrm{dB} /{ }^{\circ}$. In this study, we will denote $\alpha$ as the complement of the aspect angle and aspect conditions will be considered satisfied when $\alpha=90 \pm 1^{\circ}$.

[16] In order to understand the influence of aspect and propagation conditions on low-velocity SAIS, we build statistical distributions of the scatter throughout the night. Lowvelocity SAIS is identified using a method introduced by Ribeiro et al. [2011]. Once blocks of low-velocity SAIS are identified, the statistical backscatter distributions are built by counting scatter occurrence where the backscatter power is greater than $6 \mathrm{~dB}$, in each gate-beam cell, during the 6 hours centered on local midnight. Each cell's slant range, azimuth, and elevation are recorded to build distributions for all three of these parameters. The resulting distributions are normalized on the maximum scatter count for each night to remove daily variations in intensity. A scatter distribution value of 1 marks the region of highest scatter occurrence during a particular night, whereas a scatter distribution value of 0 means no scatter was observed. 
$28 / 0 \mathrm{ct} / 2011$

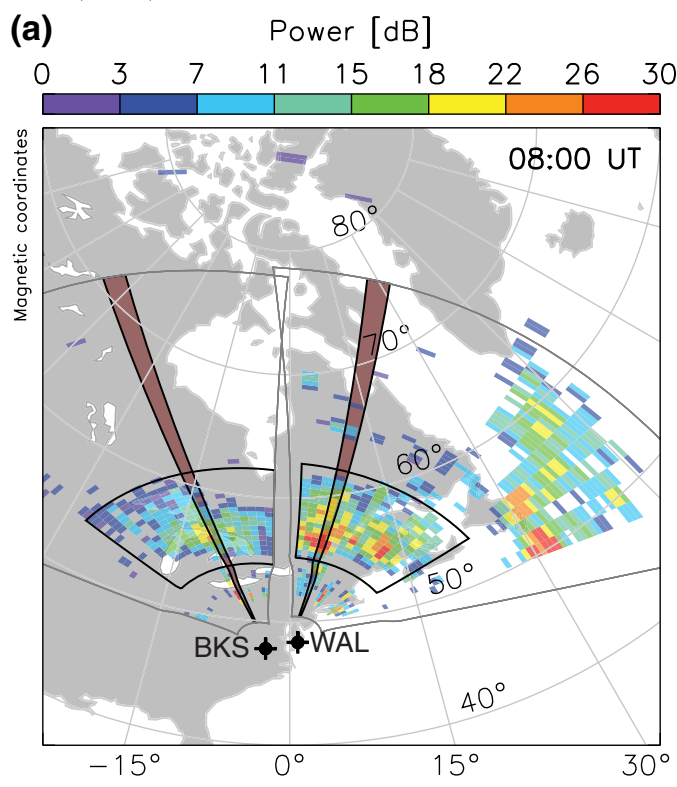

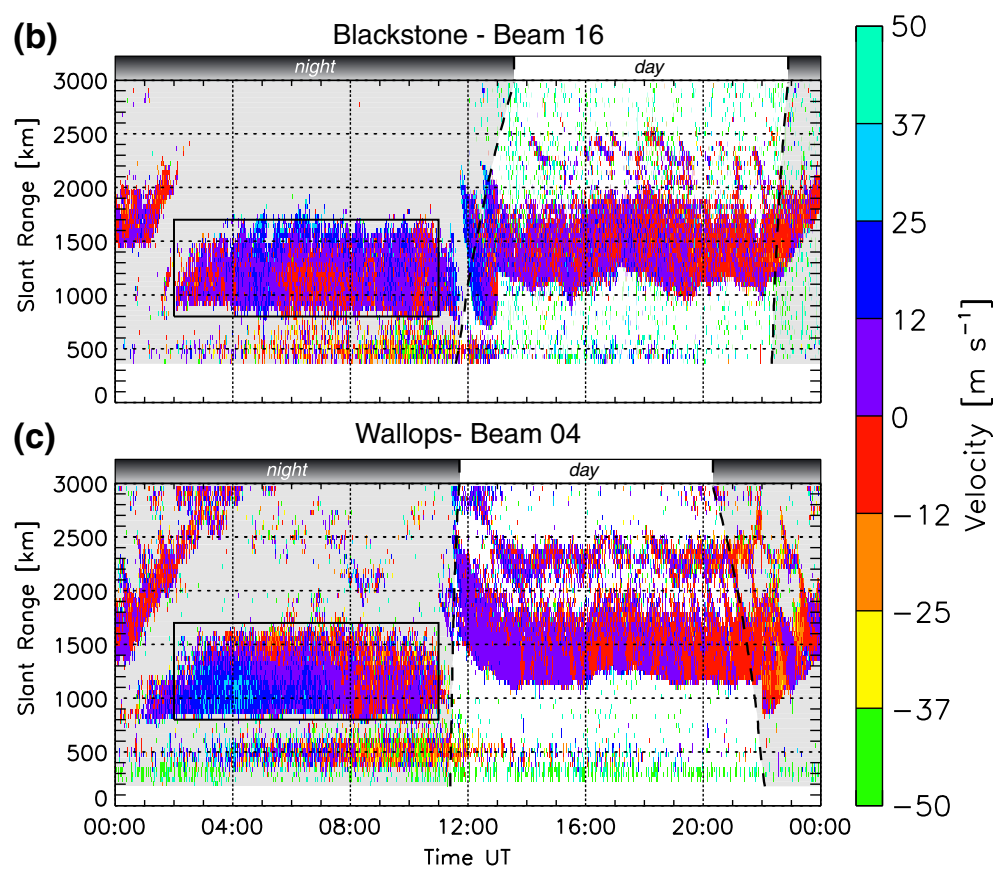

Figure 2. Sub-Auroral Ionospheric Scatter (boxed regions in all three panels) observed by the Blackstone (BKS) and Wallops (WAL) SuperDARN radars on 28 October 2011 during quiet geomagnetic time. (a) Backscatter power in the radars fields-of-view at 8:00 UT showing a wide band of ionospheric scatter (boxed regions). Beams $16\left(-25.58^{\circ} \mathrm{E}\right)$ and $4\left(58.35^{\circ} \mathrm{E}\right)$ of the Blackstone and Wallops radars are highlighted in dark pink. Range-time distribution of HF backscatter observed by (b) beam 16 of the Blackstone radar and (c) beam 4 of the Wallops radar, showing a typical time and range distribution of lowvelocity SAIS (boxed regions). Nighttime is shaded in gray and bounded by dashed traces marking the day-night terminator.

[17] Scatter distributions between November 2010 and May 2011 were searched for low-velocity SAIS. This period was selected specifically for the availability of calibrated elevation angle measurements. All events identified during this period have similar characteristics to those seen in Figure 2. Each event exhibits low velocities $(<100 \mathrm{~m} / \mathrm{s})$, lasts for several hours, extends between 500 and $2000 \mathrm{~km}$ slant range from the radar, and fades with increasing westward azimuth across the Blackstone field-of-view. For this study, we chose a representative day on 18 November 2010 , when azimuth, range, elevation, and time distributions are typical of low-velocity SAIS.

\subsection{Ray-Tracing Model}

[18] To properly interpret backscatter signatures in terms of ionospheric behavior, HF propagation in the ionosphere can be modeled using ray tracing [e.g., Hall et al., 1999]. The model employed in the present study relies on a twodimensional (2-D) formulation of Fermat's principle in the propagation plane [Coleman, 1998]. The latest International Reference Ionosphere (IRI-2012) [e.g., Bilitza and Reinisch, 2007] and International Geomagnetic Reference Field (IGRF-11) are coupled with the ray tracing. The IRI is used to compute the refractive index using the noncollisional transverse Appleton-Hartree formula as a function of electron density and signal frequency [Davies, 1990].

[19] The ray-tracing equations are implemented in a 2-D simulation domain with origin at the center of the Earth and integrated using an adaptive step Runge-Kutta Cash-Karp numerical method [Press et al., 2002]. The integration step is expressed in terms of group path length and is constrained between $1 \mathrm{~m}$ and $10 \mathrm{~km}$ for best performance/accuracy trade-off. A parallel version of the code is implemented to allow for large statistical comparisons with SuperDARN observations and real-time online access for the SuperDARN user community (available at http://vt. superdarn.org/ray-tracing).

[20] To simulate standard midlatitude SuperDARN operations, rays are typically launched at all elevation angles between $5^{\circ}$ and $55^{\circ}$ in steps of $0.1^{\circ}$, at the selected azimuth and frequency. The range of elevation angles used in the model is chosen to include typical elevation angles measured at midlatitudes. Each ray is examined for the occurrence of ionospheric or ground scatter. Figure 3 shows a typical example of HF propagation in the daytime midlatitude ionosphere obtained with the ray-tracing code described above. The electron densities are color coded and show maximum values around $250 \mathrm{~km}$ altitude. Geomagnetic field lines, plotted in pink, indicate the geomagnetic aspect geometry. Rays themselves are plotted in gray and marked with white slant-range markers at $180 \mathrm{~km}$ first (range gate 0 at the radar), then every $225 \mathrm{~km}$ (5 range gates). It can be seen that with increasing elevation angle, rays reach higher altitudes and experience less refraction until they penetrate through the ionosphere. Lower angle rays are reflected to the ground where they are identified as ground scatter. Along each ray path, segments of good aspect conditions $\left(\alpha=90 \pm 1^{\circ}\right)$ are shaded in black. 


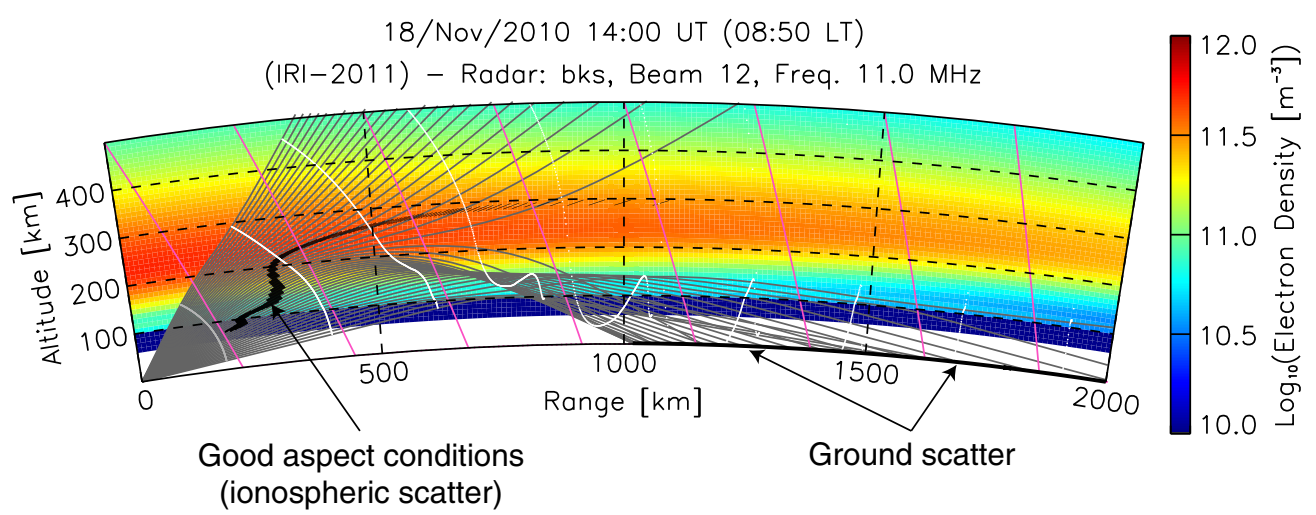

Figure 3. Ray-tracing results in an IRI generated ionosphere for beam $12\left(-14.40^{\circ} \mathrm{E}\right)$ of the Blackstone radar on 18 November 2010 at 14:00 UT. Each ray is plotted in gray and the length of a ray path to a scatter point is the slant range. Black segments mark regions where rays are within one degree of orthogonality with the background geomagnetic field lines (pink lines). Rays reaching the ground between 1000 and $2000 \mathrm{~km}$ are responsible for ground scatter. The solid white traces serve as range markers: the first trace from the transmitter is at $180 \mathrm{~km}$, and all subsequent traces are $225 \mathrm{~km}$ apart.

[21] Figure 3 identifies two types of backscatter observed by SuperDARN radars, namely ionospheric and ground scatter. Each ray reaching the ground after reflection in the ionosphere is identified as ground backscatter, and the number of rays falling into each $45 \mathrm{~km}$ slant-range bin is counted. The count is then weighted by $1 / r^{3}$, where $r$ is the slant range of a given bin (i.e., the length of a gray ray to the scatter point). The $1 / r^{3}$ weight accounts for geometric power decay in the case where the ground acts as a backscatter target. In this case, the target's size increases linearly with range, thus compensating in part for the $1 / r^{4}$ geometric power decay. Terrain geometry and reflective properties are ignored in this modeling approach.

[22] Ionospheric scatter predictions are based on the relative orientation of the background magnetic field with each ray. For field-aligned ionospheric irregularities, maximum backscatter power is obtained when the radar wave vector $\mathbf{k}$ is nearly orthogonal to the geomagnetic field $\mathbf{B}$. The angle between $\mathbf{k}$ and $\mathbf{B}$ is the complement of the aspect angle $\alpha$ and is calculated at each ray path step: if $\alpha$ is within $1^{\circ}$ of orthogonality, the current step is marked as potential ionospheric scatter, and the respective slant range $r$ and electron density $N_{e}$ are stored. Each marked ray step is then weighted by $N_{e}^{2} / r^{3}$. This weight accounts for geometric power decay and spatial variation of irregularity intensity, which is assumed to be proportional to the squared background plasma density [see Ponomarenko et al., 2009]. The scaling of irregularity intensity as $N_{e}^{2}$ holds when the relative amplitude of density fluctuations is constant throughout the ionosphere. This modeling approach effectively assumes a uniform irregularity distribution. The resulting backscatter power for each $45 \mathrm{~km}$ slant-range bin is then calculated as a sum of the weighted powers for respective steps. With this approach to modeling ionospheric backscatter, if IRI provides a realistic ionosphere, then the true irregularity distribution is the main source of differences between the modeled and observed distributions of ionospheric scatter.

[23] The example presented in Figure 3 shows the regions where ground or ionospheric scatter has been identified. It should be noted that the locations of ground and ionospheric scatter depend on ionospheric conditions and one or both types of backscatter can completely disappear. Ray-tracing results such as those presented in Figure 3 can be processed into formats compatible with SuperDARN data, such as the

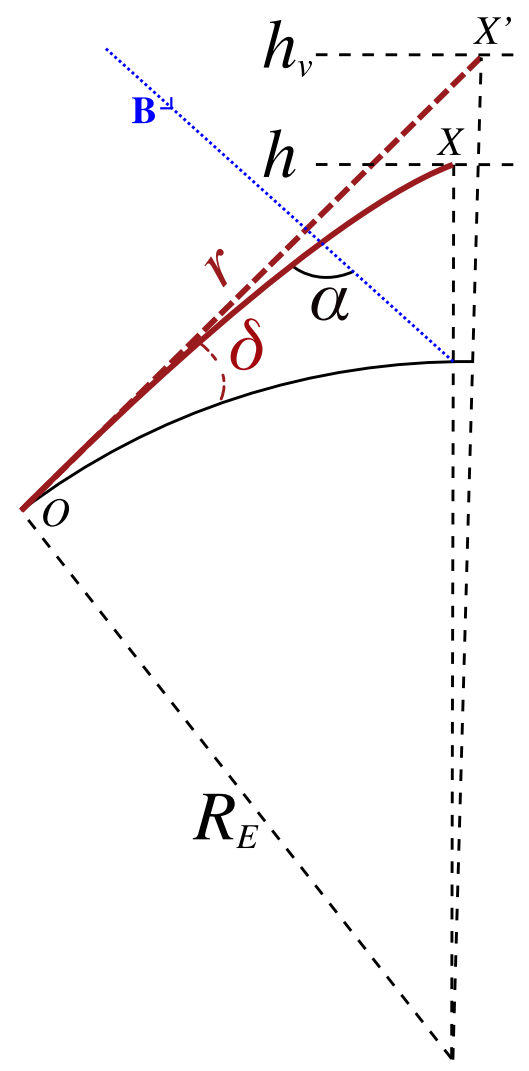

Figure 4. Ray propagation geometry. The red traces show propagation path, where the solid curve is a realistic path and the dashed line is the line-of-sight path. $h$ and $h_{v}$ are the physical and virtual altitudes, respectively, $\alpha$ is the aspect angle, $\delta$ is the elevation angle, and $r$ is the slant range along the propagation path; $R_{E}$ is the radius of the Earth and $\mathbf{B}$ is the geomagnetic field. 

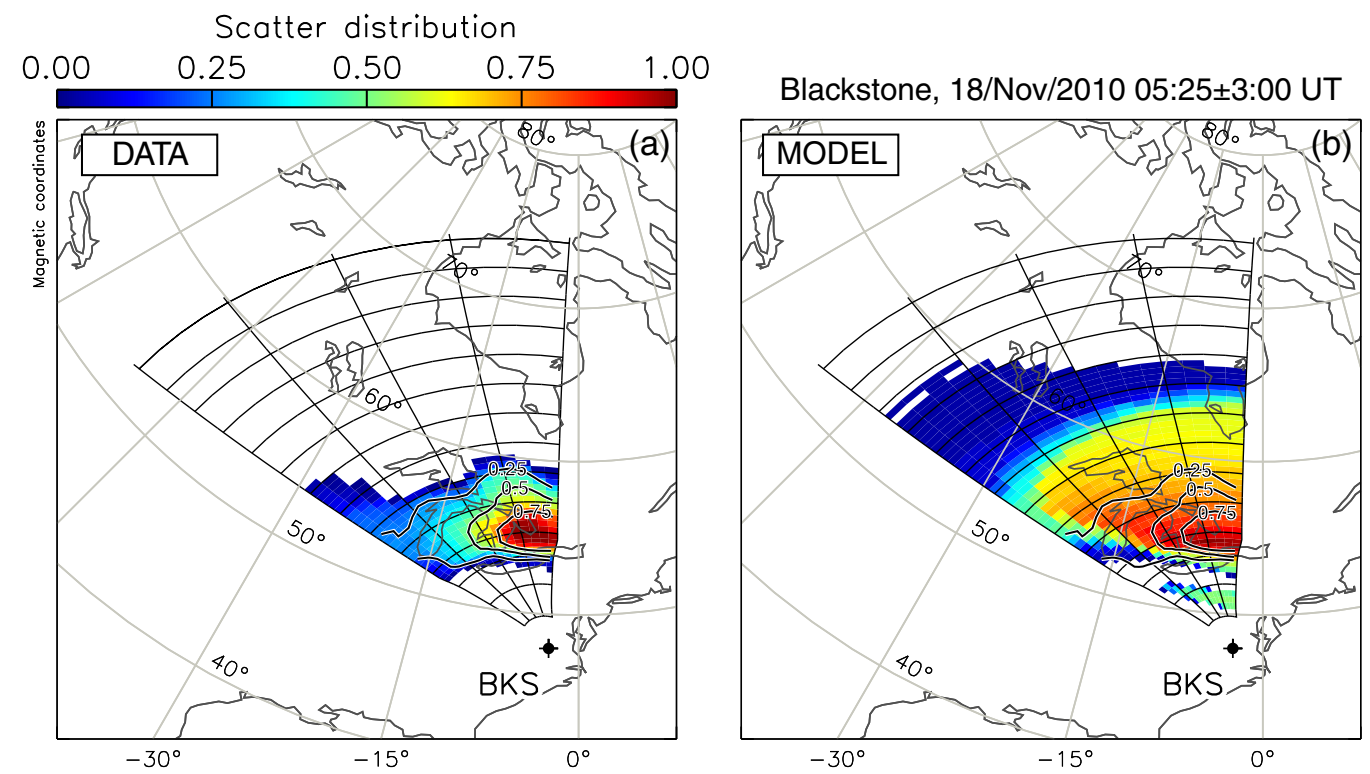

Figure 5. Azimuth distribution of low-velocity SAIS in the Blackstone SuperDARN radar field-ofview during 6 hours centered around local midnight on 18 November 2010. The field-of-view begins $180 \mathrm{~km}$ (slant range) away from the radar and is gridded every 5 slant-range gates $(225 \mathrm{~km})$ and 4 beams $(12.96$ circ), from beam 0 (westernmost) to beam 15 (easternmost). On both panels, contours of the radar data distribution at $0.25,0.5$, and 0.75 have been overlaid (solid thick black lines). (a) Radar observations.(b) Ray-tracing results. The color bar applies to both Figures 5a and 5b.

field-of-view and range-time parameters plots discussed in section 2.1 and shown in Figure 2.

\subsection{Geometric Parameters}

[24] In this section, we summarize the main parameters necessary to study HF propagation effects on ionospheric backscatter. The analysis of HF propagation requires a distinction between line-of-sight propagation and true propagation. Figure 4 illustrates this distinction, with the line-of-sight propagation following the red dashed line and the true propagation following the solid red curve. Both propagation paths start at $O$ with an elevation angle $\delta$. Both paths have the same time-of-flight $\Delta t$. The slant range $r$ is calculated as a function of the time-of-flight $\Delta t$ and the speed of light in free space $c$ as $r=c \Delta t$. In the ionosphere, the refractive index $\mu<1$, such that the group velocity $v_{g}<c$ : consequently, the slant range $r\left(O X^{\prime}\right)$ is larger than the physical length of the path $O X$. The altitude of $X^{\prime}$ is called virtual altitude and is higher than the backscatter physical height at $X$. Note that for a planar ionosphere with only vertical variations, Breit and Tuve's theorem [e.g., Davies, 1990, ch. 6] yields that $X$ and $X^{\prime}$ would be vertically aligned. Finally, the scatter occurs when the complement of the aspect angle $\alpha$ is within $1^{\circ}$ of orthogonality: this aspect condition requires increased angle of refraction (i.e., bending of the path), hence a lowering of $X$, as the magnetic field B gets closer to vertical.

[25] The concepts summarized in this section provide a framework for the propagation analysis presented next.

\section{Results}

[26] In this section, we present the main characteristics of observed and modeled backscatter distributions for
18 November 2010. Recall that this day has been picked for having azimuth, range, elevation, and time distributions typical of low-velocity SAIS. We will interpret the backscatter distributions in terms of the distribution of ionospheric irregularities in section 4 .

\subsection{Azimuth distribution}

[27] The example of low-velocity SAIS presented in Figure 2a shows most of the scatter located near the center of the combined fields-of-view of the two radars. The observed backscatter distribution across all 16 beams of the Blackstone radar during 6 hours on the night of 18 November 2010 is shown in Figure 5a, next to the model distribution obtained using the ray-tracing results (Figure $5 \mathrm{~b}$ ). The observed distribution in Figure 5a is scaled with isocontours that are also overlaid on Figure $5 \mathrm{~b}$ for reference. The experimental data show a marked offset toward the rightmost beams, a feature also seen in the model results (see Figure $5 \mathrm{~b}$ ). The region where scatter occurrence is greater than 0.5 of its maximum is located between beams 7 and $15\left(-34.10^{\circ}\right.$ and $\left.-1.96^{\circ}\right)$. This distribution bias can be interpreted either in terms of irregularity distribution or in terms of HF propagation.

[28] We use the model results from the ray tracing to analyze the relative influence of both effects on the scatter azimuth distribution. The model propagation characteristics depend on IRI generated electron densities and IGRF modeled geomagnetic field geometry. Note that the simulated distribution (Figure $5 \mathrm{~b}$ ) exhibits less dramatic azimuthal variations than the observed data distribution (Figure 5a). However, in both cases, the location of maximum scatter occurrence is between beams 7 and $15\left(-34.10^{\circ}\right.$ and $\left.-1.96^{\circ}\right)$ at approximately $900 \mathrm{~km}$ slant range. 


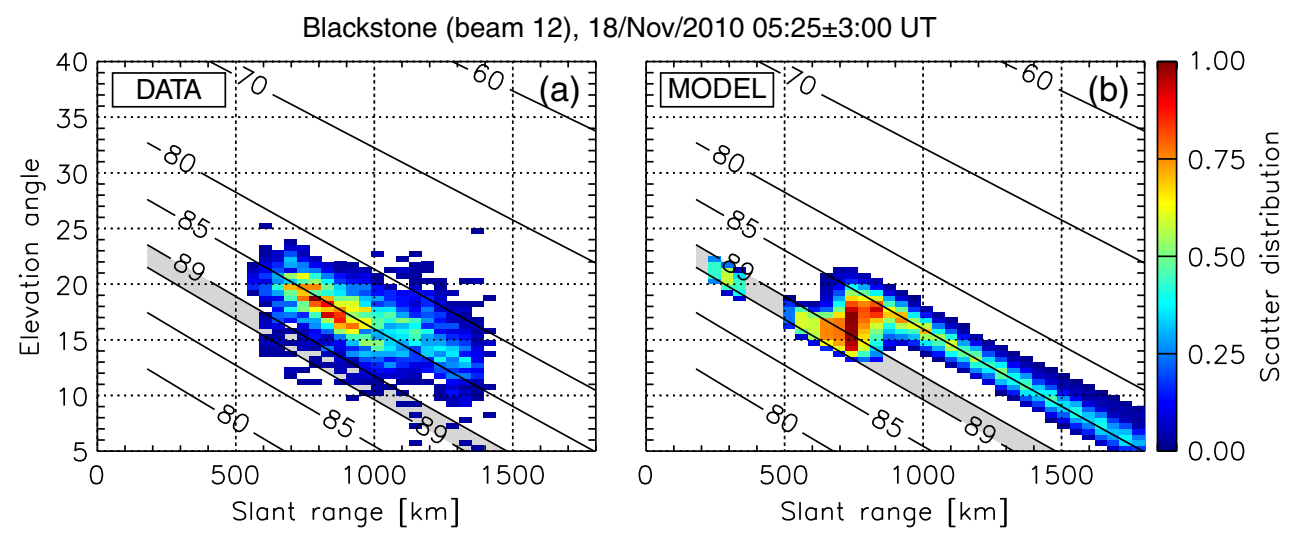

Figure 6. Elevation angle distribution of low-velocity SAIS as a function of slant range in beam 12 of the Blackstone SuperDARN radar during 6 hours centered around local midnight on 18 November 2010. Contours of the angle between the radar wave vector and the background geomagnetic field are calculated for line-of-sight propagation and overlaid. (a) Radar observations.(b) Ray-tracing results. The color bar applies to both Figures $6 \mathrm{a}$ and $6 \mathrm{~b}$.

\subsection{Slant-Range Distribution}

[29] Figure 5 is also key to revealing and understanding the range distribution. From Figures $2 b$ and $2 c$, it appears that, within a given beam, low-velocity SAIS occupies a quasi-constant slant-range band from 800 to $1600 \mathrm{~km}$. In Figure $5 \mathrm{a}$, the contour region where the scatter occurrence is greater than 0.25 of its maximum value suggests that the range extent narrows toward the leftmost beams. Figure $5 \mathrm{~b}$ captures a similar narrowing of the range distribution for scatter occurrences greater than 0.25 . However, in the region of low scatter occurrence $(<0.25)$, this slant-range narrowing is absent from both the data and simulated distributions.

[30] The simulated distribution shown in Figure 5b suggests that in an ionosphere uniformly populated with irregularities, scatter could occur at further ranges than observed in Figure 5a. Note that ray-tracing results in Figure 5b exhibit an additional region of scatter closer to the radar and detached from the main scatter patch. This closer scatter patch corresponds to potential scatter from E-region irregularities $(\sim 110 \mathrm{~km}$ altitude). Its absence in the observational data despite favorable propagation conditions indicates the absence of irregularities in the E-region. Note that this patch of predicted E-region scatter is reproduced in all subsequent distributions presented in this study. In our analysis, we focus on the region where the relative scatter occurrence is greater than $25 \%$. Both data and model results show almost identical positions of the leading slant-range edge of the scatter distribution, following the closest contour line, starting at $\sim 600 \mathrm{~km}$ in the rightmost beam (beam $15,-1.96^{\circ} \mathrm{E}$ ) to $900 \mathrm{~km}$ in the leftmost beam (beam $0,-59.28^{\circ} \mathrm{E}$ ). However, the trailing edge of the modeled distribution appears much further at $\sim 2000 \mathrm{~km}$ than observed in the data at $\sim 1300 \mathrm{~km}$.

[31] It is important to note that although we are showing the slant-range distribution in a geomagnetic coordinate system projected on the surface of the Earth, slant-range limits depend on both the horizontal and vertical distance traveled by the transmitted signal.

\subsection{Elevation Distribution}

[32] Conventional SuperDARN software does not permit to estimate the altitude of the scatter. Instead, a simplistic model is used to determine geographical coordinates of the scatter footprint [Chisham et al., 2008], which can produce a large uncertainty at ranges exceeding 1000 $\mathrm{km}$ [Yeoman et al., 2008]. Potentially, a combination of elevation angle data and ray tracing can provide more accurate information on the actual location of the effective scattering volume.

[33] Figure 6 shows the elevation angle distribution as a function of slant range in the case of observed (Figure 6a) and modeled (Figure 6b) scatter for beam $12\left(-14.40^{\circ} \mathrm{E}\right)$ of the Blackstone radar during the selected 6 hours of the night of 18 November 2010. Beam 12 was selected for being at the center of the highest scatter occurrence region in Figure 5. Notice that, to first order, the observed and modeled distributions are very similar. In the simulated distribution of Figure 6b, as in Figure 5b, we note a patch of predicted E-region scatter at closer ranges $(200-400 \mathrm{~km}$ ) and the absence of such scatter in the observations. To estimate the amount of refraction (i.e., bending of the rays) and the aspect sensitivity, aspect angle contours for the case of straight-line propagation are overlaid on both data and model distributions. If the propagation were truly line-ofsight, the observed scatter would be expected to lie close to the $\alpha=90^{\circ}$ contour line, between the $\alpha=89^{\circ}$ contours (see section 2.2).

[34] The most significant difference between Figures $6 \mathrm{a}$ and $6 \mathrm{~b}$ occurs near $700 \mathrm{~km}$ slant range. There, the model predicts a wide range of elevation angles where SAIS could be observed. However, the data only show scatter in the upper portion of these elevation angles. Since increasing elevation angles at a fixed slant range are associated with increasing altitudes, this difference suggests a lower bound to the irregularities' vertical extent.

[35] In Figures $6 \mathrm{a}$ and $6 \mathrm{~b}$, the scatter at slant ranges greater than $700 \mathrm{~km}$ is aligned with the $\alpha=85^{\circ}$ isoclines. This implies a $\sim 4^{\circ}-5^{\circ}$ elevation angle deviation from straight line. At closer slant ranges $(500-700 \mathrm{~km})$, scatter predicted by the ray tracing (Figure $6 \mathrm{~b}$ ) gets closer to the line-of-sight direction. In both modeled and observed scatter distributions, most of the scatter $(>0.5)$ is observed with elevation angles ranging from $15^{\circ}$ to $20^{\circ}$, and with slant ranges between 700 and $1000 \mathrm{~km}$. We consider that the 
high degree of similarity between these distributions indicates that the model realistically reflects actual propagation conditions.

[36] We also consider the width of the scatter distribution along the elevation axis. We restrict our analysis to the part of the distribution where scatter occurrence is greater than $50 \%$ of its maximum value $(>0.5)$ in order to maximize the statistical significance of the backscatter elevation. With this constraint, the width of the elevation distribution is close to the angular distance between the $\alpha=89^{\circ}$ isoclines. This means that for the scatter considered here, the $1^{\circ}$ ad hoc aspect sensitivity condition appears to be valid.

[37] Elevation, angle of refraction, and slant range can be combined to estimate altitude and ground-range distributions of the observed low-velocity SAIS. A zeroth-order estimate for the center of the scatter distribution at 800 $\mathrm{km}$ slant range and $18^{\circ}$ elevation yields a physical altitude $h \simeq 240 \mathrm{~km}$. This indicates that the assumption by Greenwald et al. [2006] that SAIS originates from the ionospheric F-region was correct.

\section{Discussion}

[38] We analyze the azimuth, slant range, and elevation distributions of low-velocity ionospheric backscatter at midlatitudes presented in section 3 to decouple $\mathrm{HF}$ propagation effects from the observations and so deduce information on the spatial distribution of the ionospheric irregularities. The multiple similarities and few differences between the observed and modeled distributions are key to this discussion.

\subsection{IRI Effects on Modeled HF Propagation at Midlatitude}

[39] The modeling results rely on the IRI to predict scatter distributions. Consequently, the IRI is an important factor influencing the comparison between the modeled and observed distributions presented in Figures 5 and 6. Previous comparison between midlatitude SuperDARN data and IRI-based ray tracing during quiet geomagnetic periods has shown good correlation for ground scatter events [de Larquier et al., 2011].

[40] The case of ionospheric scatter is more complex as the ray-tracing model assumes uniform distribution of ionospheric irregularities so that it can only predict potential scatter distributions but cannot account for the presence or absence of irregularities required to observe ionospheric scatter. The IRI is used to determine the amount of vertical refraction a ray path experiences, thus determining the region where the ray can satisfy aspect conditions $(\alpha=$ $\left.90 \pm 1^{\circ}\right)$ so that irregularities can be observed. We investigated the sensitivity of the modeled spatial distributions of the backscatter to $20 \%$ variations in IRI maximum height and electron density of F2 layer. We observed only $\sim 10 \%$ variations in the effective altitude and ground range of the scatter maximum occurrence. This means that the modeled ionospheric scatter distributions are only marginally affected by the intrinsic uncertainties of the IRI model.

[41] This is not unexpected because the quiet time midlatitude ionosphere is an ideal candidate for empirical models such as IRI. The high adequacy of IRI under the conditions of interest to this study implies that differences between modeled and observed backscatter distributions provide meaningful information about the distribution of irregularity.

\subsection{Irregularities Altitude Range}

[42] An important yet elusive parameter in HF observations is the altitude of the backscattering irregularities. Studies based on SuperDARN observations generally use a simple stepped linear model depending on slant range only [Chisham et al., 2008]. More accurate models have also been used to estimate backscatter altitude [e.g., Chisham et al., 2008; Liu et al., 2012]. If accurate elevation angle measurements are available, then the virtual altitude $h_{v}$ (see Figure 4) can be calculated. However, the actual altitude depends on the amount of vertical refraction.

[43] In the case of low-velocity SAIS, we benefit from a relatively quiet and weak background ionosphere. Figure 6 shows that the modeled scatter follows the same isocline $\left(85^{\circ}\right)$ as the observed scatter at slant ranges $700-1400 \mathrm{~km}$. This suggests that the ray tracing adequately reproduces vertical refraction, such that it can provide a reliable estimate of the observed scatter altitude. Furthermore, the deviation from line-of-sight appears to be small $\left(<0.5^{\circ} / 100 \mathrm{~km}\right)$, indicating minimal refraction. In this case the relation between virtual altitude $h_{v}$ and physical altitude $h$ can be approximated as a linear function of slant range $r$ such as $h=h_{v}-\gamma r$, where $\gamma$ is a dimensionless constant expressing the bending of the ray paths during the night of 18 November 2010. The coefficient $\gamma$ is calculated from the known virtual and physical height of the modeled scatter distributions. Figure $7 \mathrm{a}$ shows the physical versus virtual altitude of the modeled scatter (blue markers), as well as the result of a linear regression through these points (red line). The slope of the linear regression is the coefficient $\gamma$.

[44] The result of this transformation from elevation to physical altitude of observed SAIS is presented in Figure 7b. For consistency, the ray-tracing altitude distribution shown in Figure $7 \mathrm{c}$ is obtained with the same transformation rather than directly from the modeled altitude. On the same graphs, we plot the $\alpha=89^{\circ}$ isoclines for line-of-sight propagation for beams 12 (solid curves) and 0 (dashed curves). Most of the scatter is observed between 220 and $320 \mathrm{~km}$ altitude, typically corresponding to the nighttime bottomside F-region ionosphere (on the night considered here, IRI places the F-region peak at $340 \mathrm{~km}$ ). Note also that the model predicts favorable propagation conditions at E-region altitudes but experimentally no scatter is observed, indicating the absence of E-region irregularities. To our knowledge, this is the first experimental estimation of the height of low-velocity SAIS.

[45] It is worth noting that the bottom-side F-region is characterized by a strong vertical electron density gradient. Moreover, at midlatitudes, this gradient has a significant component in the direction perpendicular to the geomagnetic field. Electron density or temperature gradients perpendicular to the magnetic field are an important aspect of several plasma instabilities, [Hudson and Kelley, 1976], such as the TGI or Gradient Drift Instability [Baker et al., 1986]. The confinement of the observed backscatter to the bottom-side F-region may therefore indicate that the irregularities are produced by one of the above instabilities. 

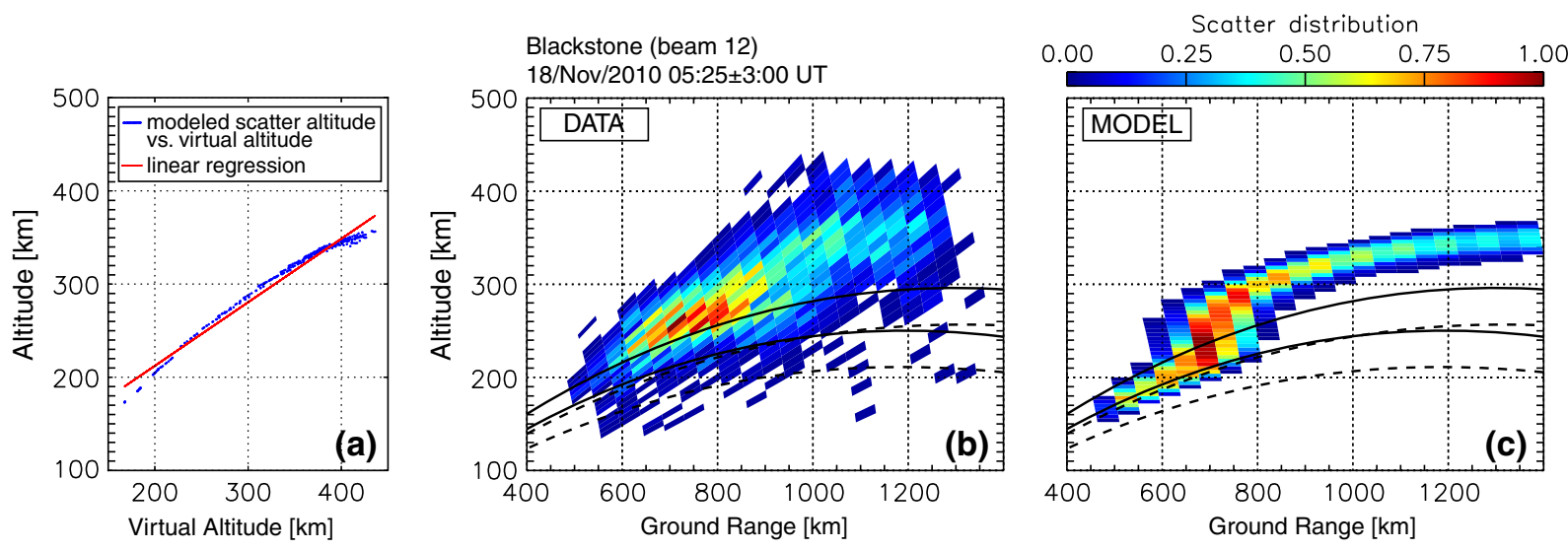

Figure 7. Altitude distributions for the Blackstone SuperDARN radar during 6 hours centered around local midnight on 18 November 2010. (a) Altitude versus virtual altitude of the modeled scatter distribution (blue dots) used to estimate the linear transformation between altitude and virtual altitude (red line). (b) Radar observations. (c) Ray-tracing results. Physical altitude of the observed backscatter (data) is calculated from slant range, virtual height, and a linear coefficient derived from model results as shown in Figure 7a. The two solid curves and two dashed curves in Figures $7 \mathrm{~b}$ and $7 \mathrm{c}$ mark the regions where the complementary of the aspect angle $\alpha=90 \pm 1^{\circ}$ for beam 12 (solid) and beam 0 (dashed), respectively.

\subsection{Horizontal Extent of Irregularities}

[46] We now consider the horizontal extent of the irregularities implied by the azimuth and slant-range backscatter distributions. Several previous studies analyzed statistical distributions of irregularities at high and midlatitudes during moderate to active geomagnetic periods [e.g., Hosokawa et al., 2002; Hughes et al., 2002; Parkinson et al., 2002; Nishitani and Ogawa, 2005; Kane et al., 2012]. However, none of them have focused specifically on low-velocity SAIS and the distinctive features of the backscatter distribution within the radar fields-of-view.

[47] The most prominent feature, captured in both data and model, is the azimuthal bias (see Figure 5). To assist our discussion, the azimuths with respect to geomagnetic North for the extreme beams of the Blackstone and Wallops radars are presented in Table 1. From this table, it is apparent that the scatter is concentrated in the meridional beams. This still does not preclude the possibility that irregularities are simply confined to this particular region. However, similar low-velocity SAIS is observed with other SuperDARN radars, with the same bias toward the most meridional beams (not shown).

[48] This bias can be consistently explained in terms of propagation geometry. To visualize this geometry, Figure 8 represents the idealized situation at the Blackstone radar, where the average magnetic field dip angle is $70^{\circ}$, two beams are looking North and East with an elevation angle of $20^{\circ}$, and the Earth is flat. Figure 8 a shows a three-dimensional view of the two signals propagating in a straight line (i.e., no refraction), one northward along a magnetic meridian, and the other eastward perpendicularly to the same meridian. Figure $8 \mathrm{~b}$ shows that in the meridional direction, the wave vector achieves perpendicularity with a geomagnetic field line without refraction at some altitude, thus satisfying aspect conditions and allowing irregularities to be observed. However, Figure $8 \mathrm{c}$ shows that the wave vector in the zonal direction is further away from good aspect conditions at the same altitude and requires either increased refraction or a lower elevation angle to achieve perpendicularity. Consequently, under fixed ionospheric conditions (constant refraction), moving the propagation direction away from the magnetic meridian shifts aspect-friendly areas to further ranges and lower altitudes. As a result, under quiet nighttime conditions characterized by weak refraction, off-meridional beams should see ionospheric scatter moving further away from the radar with reduced occurrence, as observed in Figure 5.

[49] Further illustration of this propagation effect is given in Figure 7. The solid and dashed contours mark regions of good line-of-sight aspect conditions for a mostly meridional beam (beam 12) and the most zonal beam (beam 0), respectively. For the zonal beam, the region of good aspect conditions occurs at lower altitudes than for the meridional beam. Under uniform ionospheric conditions within the radar field-of-view, these line-of-sight contours reflect the relative position of good aspect condition regions of a meridional and zonal beam. Thus, zonal beams are constrained to lower altitudes than meridional beams. Since scatter occurrence declines sharply with beam direction moving away from magnetic North, one can assume that the irregularities are confined to the F-layer and disappear at lower altitudes. This result points to the effect of HF propagation on the observable region of irregularities. An important implication is that the backscattering irregularities likely extend beyond the azimuth limits of the observed scatter, covering a much larger longitude swath of the midlatitude ionosphere

Table 1. Beam-Azimuth Conversion with Respect to Geomagnetic North for the Blackstone and Wallops SuperDARN Radars ${ }^{\mathrm{a}}$

\begin{tabular}{lccc}
\hline Radar & First Beam & Last Beam & Beam Separation \\
\hline$b k s$ & $-59.28^{\circ} \mathrm{E}$ & $-1.96^{\circ} \mathrm{E}$ & $3.86^{\circ}$ \\
wal & $-1.36^{\circ} \mathrm{E}$ & $84.35^{\circ} \mathrm{E}$ & $3.24^{\circ}$ \\
\hline
\end{tabular}

${ }^{a}$ Note that beams are always numbered from West to East. 
(a)

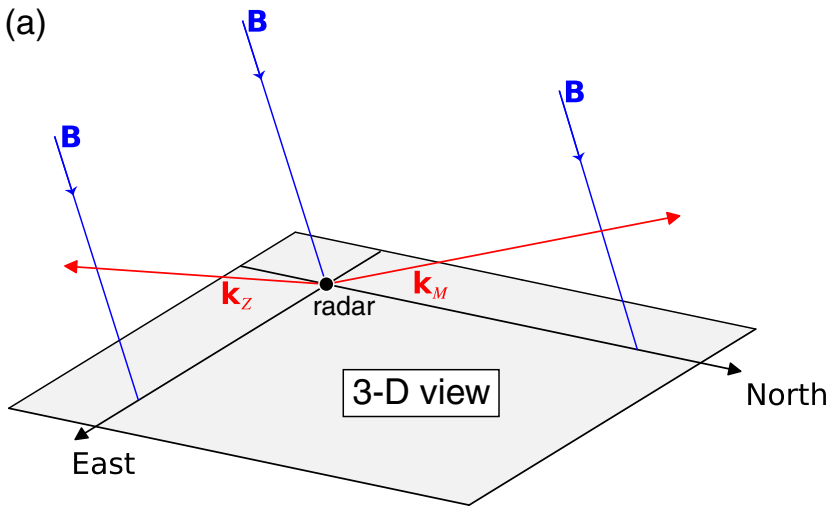

(b)

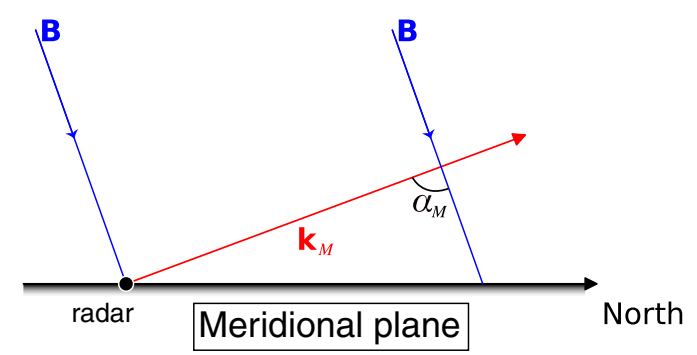

(c)

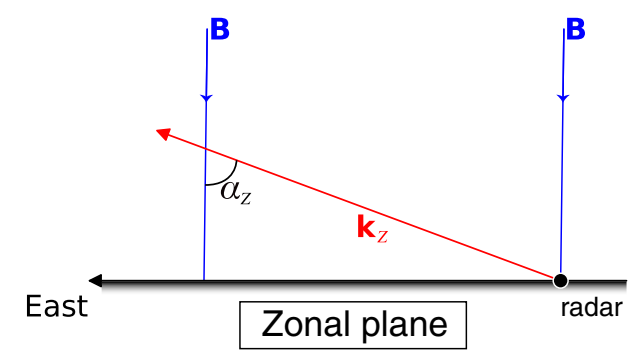

Figure 8. Idealized illustration of the effect of propagation azimuth on aspect geometry at subauroral latitudes for a flat Earth. $\mathbf{k}_{M}$ and $\mathbf{k}_{Z}$ denote the wave vector in the meridional and zonal directions, respectively. $\mathbf{B}$ is the geomagnetic field with a fixed dip angle representative of the Blackstone SuperDARN radar. North and East are indicated with respect to geomagnetic North. (a) 3-D view. (b) 2-D side view along a meridional beam. (c) 2-D side view along a zonal beam. $\alpha_{M}$ is closer to $90^{\circ}$ than $\alpha_{Z}$, indicating that a lower elevation angle or increased refraction is required in the zonal plane to achieve good aspect conditions.

than suggested by the apparent azimuthal distribution in the radar data.

[50] The propagation constraints on the altitude and range of good aspect conditions also explains why the leading edge of the modeled and observed scatter shown in Figures $5 \mathrm{a}$ and $5 \mathrm{~b}$ match very well. As the radar scans toward off-meridional beams, aspect conditions are lowered and pushed further in range, which describes the slanted leading edge of the scatter distribution across the field-of-view. However, the mismatch in the trailing edge between the model and data distributions remains unexplained and could be interpreted either as a horizontal or vertical limit on the spatial extent of irregularities. This information would provide valuable insight into the underlying plasma instabilities, such as the relative importance of vertical and horizontal gradients or the identification of a source region. According to Figure $7 \mathrm{c}$, for a given beam direction, increasing ground range leads to increasing height with favorable aspect conditions. Additionally, the furthest distribution contour in Figure 5a appears to follow a constant slant-range line rather than a constant geomagnetic latitude. These observations argue that the range limit to the observed scatter distribution is likely due to the absence of irregularities at altitudes exceeding the F-region peak.

[51] The high similarity between experimental and modeled spatial distributions of the HF backscatter argues that the observability of the nighttime echoes is subject to aspect angle restrictions. The matching close-range and offmeridional limits suggest that the actual horizontal extent of the ionospheric irregularities spreads well beyond the fieldof-view of the radar. Additionally, the boundary mismatch at the far ranges points at a limited vertical extent of the scatterers, which seems to be confined to the bottom part of the F-region. These results combined with the results from Ribeiro et al. [2012] provide a full description of the spatial and temporal characteristics of nightside quiescent midlatitude irregularities.

\section{Summary}

[52] In this paper we have analyzed the spatial distributions of low-velocity Sub-Auroral Ionospheric Scatter (SAIS) and their implications for understanding a prominent type of quiet time subauroral irregularities. The occurrence of such scatter shows a bias toward meridional beam directions. It also shows reduced slant range at the leading edge of the scatter for the most meridional beams but quasiconstant slant range for the trailing edge of the scatter across all beams. We have demonstrated that the limited spatial extent of this category of ionospheric backscatter within SuperDARN fields-of-view is a consequence of HF propagation and the finite extent of irregularity altitude. We were able to show that the observed backscatter distributions from the decameter-scale ionospheric irregularities in the midlatitude ionosphere are consistent with a $1^{\circ}$ aspect sensitivity. Propagation effects were shown to control the altitude and range extents of the irregularities visible to the SuperDARN radars. This indicates that the irregularities extend over wide regions of the midlatitude ionosphere, but their appearance within radars fields-of-view is constrained by propagation geometry. Backscatter also seems to be constrained by the finite vertical extent of the irregularities. For the first time, the altitudes of the subauroral ionospheric irregularities is estimated to extend between 200 and $300 \mathrm{~km}$, which agrees with previous assumptions about SAIS. Conclusions presented in this paper further reinforce the prominence of such irregularities, both temporally due to their high occurrence rate and durations and spatially as evidenced in this study. These findings clarify our understanding of the nature of plasma instability responsible for the observed irregularities. Instruments such as ISRs or in situ rocket measurements could be used to obtain simultaneous complementary plasma diagnostics.

[53] Acknowledgments. The Virginia Tech authors acknowledge the support of NSF under grant AGS-0946900.

[54] Robert Lysak thanks Kjellmar Oksavik and another reviewer for their assistance in evaluating this paper. 


\section{DE LARQUIER ET AL.: SUBAURORAL IONOSPHERIC IRREGULARITIES}

\section{References}

Baker, K., and S. Wing (1989), A new magnetic coordinate system for conjugate studies at high latitudes, J. Geophys. Res., 94(A7), 9139-9143.

Baker, K., R. Greenwald, A. Walker, P. Bythrow, L. Zanetti, T. Potemra, D. Hardy, F. Rich, and C. Rino (1986), A case study of plasma processes in the dayside cleft, J. Geophys. Res., 91(A3), 3130-3144.

Bates, H. F., and P. R. Albee (1969), Aspect sensitivity of hf auroral echoes, J. Geophys. Res., 74(5), 1164-1168.

Bates, H. F., and P. R. Albee (1970), Aspect sensitivity of F-layer HF backscatter echoes, J. Geophys. Res., 75(1), 165-170.

Bilitza, D., and B. Reinisch (2007), Improvements and new parameters, $J$. Adv. Space Res., 42(4), 599-609.

Chisham, G., T. Yeoman, and G. Sofko (2008), Mapping ionospheric backscatter measured by the SuperDARN HF radars-part 1: A new empirical virtual height model, Ann. Geophys., 26, 823-841.

Chisham, G., et al. (2007), A decade of the Super Dual Auroral Radar Network (SuperDARN): Scientific achievements, new techniques and future directions, Surv. Geophys., 28, 33-109.

Clausen, L. B. N., et al. (2012), Large-scale observations of a subauroral polarization stream by midlatitude SuperDARN radars: Instantaneous longitudinal velocity variations, J. Geophys. Res., 117, A05306, doi:10.1029/2011JA017232.

Coleman, C. J. (1998), A ray tracing formulation and its application to some problems in over-the-horizon radar, Radio Sci., 33(4), 1187-1197.

Davies, K. (1990), Ionospheric Radio, 580 p., The Institution of Engineering and Technology, London, U. K.

de Larquier, S., J. M. Ruohoniemi, J. B. H. Baker, N. R. Varrier, and M. Lester (2011), First observations of the midlatitude evening anomaly using Super Dual Auroral Radar Network (SuperDARN) radars, J. Geophys. Res., 116, A10321, doi:10.1029/2011JA016787.

Fejer, B., and M. C. Kelley (1980), Ionospheric irregularities, Rev. Geophys., 18(2), 401-454.

Foster, J., D. Tetenbaum, C. Del Pozo, J.-P. St-Maurice, and D. Moorcroft (1992), Aspect angle variations in intensity, phase velocity, and altitude for high-latitude 34-cm E region irregularities, J. Geophys. Res., 97(A6), $8601-8617$.

Fremouw, E., C. Rino, R. Livingston, and M. Cousins (1977), A persistent subauroral scintillation enhancement observed in Alaska, Geophys. Res. Lett., 4(11), 539-542.

Greenwald, R., et al. (1995), DARN/SuperDARN, Space Sci. Rev., 71(1), 761-796.

Greenwald, R. A., K. Oksavik, P. J. Erickson, F. D. Lind, J. M. Ruohoniemi, J. B. H. Baker, and J. W. Gjerloev (2006), Identification of the temperature gradient instability as the source of decameter-scale ionospheric irregularities on plasmapause field lines, Geophys. Res. Lett., 33, L18105, doi:10.1029/2006GL026581.

Grocott, A., S. Milan, J. Baker, M. Freeman, M. Lester, and T. Yeoman (2011), Dynamic subauroral ionospheric electric fields observed by the Falkland Islands radar during the course of a geomagnetic storm, $J$. Geophys. Res., 116, A11202, doi:10.1029/2011JA016763.

Hall, G. E., J. W. MacDougall, J. F. Cecile, D. R. Moorcroft, and J. P. St-Maurice (1999), Finding gravity wave source positions using the Super Dual Auroral Radar Network, J. Geophys. Res., 104(A1), 67-78.

Heelis, R. (2004), Electrodynamics in the low and middle latitude ionosphere: A tutorial, J. Atmos. Sol.-Terr. Phys., 66, 825-838.

Hosokawa, K., M. Sugino, M. Lester, N. Sato, A. Yukimatu, and T. Iyemori (2002), Simultaneous measurement of duskside subauroral irregularities from the CUTLASS Finland radar and EISCAT UHF system, J. Geophys. Res., 107(A12), 1457, doi:10.1029/2002JA009416.

Huba, J., G. Joyce, S. Sazykin, R. Wolf, and R. Spiro (2005), Simulation study of penetration electric field effects on the low- to mid-latitude ionosphere, Geophys. Res. Lett., 32, L23101, doi:10.1029/2005GL024162.

Hudson, M. K., and M. C. Kelley (1976), The temperature gradient drift instability at the equatorward edge of the ionospheric plasma trough, $J$ Geophys. Res., 81(22), 3813-3918.

Hughes, J. M., W. A. Bristow, R. A. Greenwald, and R. J. Barnes (2002), Determining characteristics of HF communications links using SuperDARN, Ann. Geophys., 20(7), 1023-1030.
Hysell, D., M. Kelley, Y. M. Yampolski, V. Beley, A. Koloskov, P. Ponomarenko, and O. Tyrnov (1996), HF radar observations of decaying artificial field-aligned irregularities, J. Geophys. Res., 101(A12), 26,981-26,993.

Kane, T. A., R. A. Makarevich, and J. C. Devlin (2012), HF radar observations of ionospheric backscatter during geomagnetically quiet periods Ann. Geophys., 30, 221-233.

Kelley, M., B. Fejer, and C. Gonzales (1979), An explanation for anomalous equatorial ionospheric electric fields associated with a northward turning of the interplanetary magnetic field, Geophys. Res. Lett., 6(4), 301-304.

Kelley, M. C. (2009), The Earth's Ionosphere, Plasma Physics And Electrodynamics, 2nd ed., International Geophysics Series, Elsevier, San Diego, Calif.

Kunduri, B., J. Baker, J. Ruohoniemi, L. Clausen, A. Grocott, E. Thomas, M. Freeman, and E. Talaat (2012), An examination of inter-hemispheric conjugacy in a subauroral polarization stream, J. Geophys. Res., 117, A08225, doi:10.1029/2012JA017784.

Liu, E., H. Hu, R. Liu, Z. Wu, and M. Lester (2012), An adjusted location model for SuperDARN backscatter echoes, Ann. Geophys., 30, 1769.

Milan, S. E., T. K. Yeoman, M. Lester, E. C. Thomas, and T. B. Jones (1997), Initial backscatter occurrence statistics from the CUTLASS HF radars, Ann. Geophys., 15(6), 703-718.

Nishitani, N., and T. Ogawa (2005), Model calculations of possible ionospheric backscatter echo area for a mid-latitude HF radar, Adv. Polar Upper Atmos. Res., 19, 55-62.

Oksavik, K., R. Greenwald, J. Ruohoniemi, M. Hairston, L. Paxton, J. Baker, J. Gjerloev, and R. Barnes (2006), First observations of the temporal/spatial variation of the sub-auroral polarization stream from the SuperDARN Wallops HF radar, Geophys. Res. Lett, 33, L12104, doi:10.1029/2006GL026256.

Oksman, J., H. Möller, and R. Greenwald (1979), Comparisons between strong HF backscatter and VHF radar aurora, Radio Sci., 14(6), 1121-1133.

Parkinson, M., J. Devlin, P. L. Dyson, M. Pinnock, H. Ye, R. Morris, and C. Waters (2002), Diurnal, seasonal, and geomagnetic activity variations in the occurrence of decametre-scale irregularities in the auroral and subauroral ionosphere, in Proceedings of the Workshop on the Applications of Radio Science, Refereed Paper $G$, vol. 9, Leura, New South Wales.

Ponomarenko, P. V., J.-P. St-Maurice, C. L. Waters, R. G. Gillies, and A. V. Koustov (2009), Refractive index effects on the scatter volume location and Doppler velocity estimates of ionospheric HF backscatter echoes, Ann. Geophys., 27, 4207-4219.

Press, W. H. S. A. Teukolsky, W. T. Vetterling, and B. P. Flannery (2002), Numerical Recipes in C: The Art of Scientific Computing, 2nd ed., Cambridge University Press, New York.

Ribeiro, A. J., J. M. Ruohoniemi, J. B. H. Baker, L. B. N. Clausen, and S. de Larquier (2011), A new approach to identifying ionospheric backscatter in midlatitude SuperDARN data, Radio Sci., 46, RS4011, doi:10.1029/2011RS004676.

Ribeiro, A. J., J. M. Ruohoniemi, J. B. H. Baker, L. B. N. Clausen, R. A. Greenwald, and M. Lester (2012), A survey of plasma irregularities as seen by the midlatitude Blackstone SuperDARN radar, J. Geophys. Res., 117, A02311, doi:10.1029/2011JA017207.

Ruohoniemi, J. M., and K. B. Baker (1998), Large-scale imaging of highlatitude convection with Super Dual Auroral Radar Network HF radar observations, J. Geophys. Res., 103(A9), 20,797-20,811.

Su, S.-Y., C. Liu, H. Ho, and C. Chao (2006), Distribution characteristics of topside ionospheric density irregularities: Equatorial versus midlatitude regions, J. Geophys. Res., 111, A06305, doi:10.1029/2005JA011330.

Titheridge, J. E. (1995), Winds in the ionosphere - a review, J. Atmos. Sol.Terr. Phys., 57(14), 1681-1714.

Tsugawa, T., Y. Otsuka, A. Coster, and A. Saito (2007), Mediumscale traveling ionospheric disturbances detected with dense and wide TEC maps over North America, Geophys. Res. Lett., 34, L22101, doi:10.1029/2007GL031663.

Tsunoda, R. (1988), High-latitude F region irregularities: A review and synthesis, Rev. Geophys., 26(4), 719-760.

Yeoman, T, G Chisham, L Baddeley, R Dhillion, T Karhunen, T. Robinson, A. Senior, and D. Wright (2008), Mapping ionospheric backscatter measured by the SuperDARN HF radars - part 2: Assessing SuperDARN virtual height models, Ann. Geophys., 26(4), 843-852. 